\title{
A regulamentação da propaganda de alimentos no Brasil: convergências e conflitos de interesses
}

\section{Regulation of food advertising in Brazil: convergence and conflicts of interest}

\section{La regulación de la publicidad de alimentos en Brasil: convergencias y conflictos de interés}

Patricia Henriques 1,2 Patricia Camacho Dias 1 Luciene Burlandy 1

\footnotetext{
${ }^{1}$ Faculdade de Nutrição, Universidade Federal

Fluminense, Niterói, Brasil.

2 Escola Nacional de Saúde

Pública Sergio Arouca,

Fundação Oswaldo Cruz,

Rio de Janeiro, Brasil.

Correspondência

P. Henriques

Faculdade de Nutrição,

Universidade Federal

Fluminense.

Rua Mario Santos Braga 30,

Campus do Valonguinho,

Niterói, $R J$

24020-140, Brasil.

patriciah@uol.com.br
}

\begin{abstract}
This study conducted a comparative analysis of a bill to regulate advertising for unhealthy food and beverages with low nutritional value, submitted to public hearings in 2006, and the Res olution passed in 2010. The analysis was based on data from official documents pertaining to food advertising, identification of key actors, and their underlying arguments. As approved the Resolution is less detailed and rigorous from the regulatory perspective. The final documents removed bans and requirements on the format, content, and theme of food advertising, especially targeting children. Stronger discussion is needed on the constitution of the public arena, public interests, and the mechanisms and processes to help guarantee them.
\end{abstract}

Products Publicity Control; Food Security; Advertisements

\section{Resumo}

O presente estudo objetivou desenvolver uma análise comparativa entre o documento proposto para regulamentar a publicidade de alimentos não saudáveis e de bebidas de baixo valor nutricional, levado à consulta pública em 2006, e a Resolução aprovada em 2010. A análise se pautou em dados provenientes de documentos legais referentes à regulamentação da propaganda de alimentos, na identificação dos atores-chave e dos argumentos que fundamentaram seus discursos. Verificou-se que a Resolução aprovada se apresenta menos detalhada e rigorosa sob o ponto de vista regulatório. Foram retiradas proibições e exigências sobre o formato, o conteúdo e os temas das propagandas de alimentos, em especial as voltadas ao público infantil. Faz-se necessário fortalecer a discussão sobre o que é a esfera pública, como ela se constrói, o que são interesses públicos e quais mecanismos e processos podem contribuir para garanti-los.

Controle da Publicidade de Produtos; Segurança Alimentar e Nutricional; Anúncios 


\section{Introdução}

As mudanças econômicas, sociais e demográficas ocorridas nas últimas décadas afetaram o cotidiano de vida e o perfil de práticas alimentares em diferentes contextos geopolíticos. Os reflexos no processo saúde-doença e no estado nutricional da população brasileira configuram um quadro alarmante de crescimento da obesidade e doenças associadas 1 .

As doenças crônicas não transmissíveis (DCNT) atingem cerca de 36 milhões de pessoas e são responsáveis pela maioria das mortes no mundo, sendo condicionadas pelo perfil alimentar, de atividade física e modos de vida 2 . No Brasil, correspondem a $72 \%$ das causas de mortes, afetando fortemente as camadas pobres e grupos vulneráveis 3 .

A coexistência de problemas de desigualdades de acesso à alimentação saudável e uma maior disponibilidade de produtos industrializados altamente processados, que apresentam relação favorável em termos de custo-saciedadesabor, parece contribuir de forma significativa para esse cenário ${ }^{4}$.

A compreensão dos condicionantes desse quadro tem despertado o interesse de especialistas que apontam que, dentre múltiplos fatores, a mídia televisiva influencia de forma negativa as preferências alimentares. Sugere-se que as propagandas têm contribuído para a conformação de um ambiente "obesogênico" que dificulta a adoção de escolhas saudáveis 5 . As mensagens sobre alimentação, veiculadas pelos meios de comunicação, merecem destaque, já que a mídia tem exercido papel fundamental na formação de novos hábitos alimentares, em especial de crianças. Tal cenário se agrava diante da constatação de que a divulgação da informação está mais pautada em critérios publicitários do que informativos sobre as características nutricionais acerca dos produtos. Isso dificulta a clara compreensão por parte dos consumidores sobre as diversas características e propriedades desses alimentos e sobre as implicações do seu consumo 6 .

Assim, pode-se considerar que o marketing de fast food, alimentos e bebidas densamente energéticos e pobres em micronutrientes é um "provável" fator condicionante da obesidade $7 \mathrm{e}$, portanto, vem sendo foco de debates internacionais, especialmente com relação às crianças 8 . Vários estudos evidenciam a exposição excessiva de crianças à publicidade de alimentos não saudáveis na televisão e indicam que a maior parte do marketing se refere a alimentos com alto teor de gordura, açúcar e sal ${ }^{9}$. Além disso, ressaltam as repercussões desse processo nas práticas de compra, no perfil de consumo e no estado nutricional 10,11,12,13,14. Nesse contexto, a regulamentação da propaganda e da publicidade de alimentos pode assumir um papel estratégico como medida de proteção, particularmente voltada para o público mais vulnerável aos apelos promocionais, como o infantil.

Diversos países têm adotado medidas legais para limitar a publicidade de alimentos, seja proibindo a propaganda de produtos considerados não saudáveis, seja restringindo o horário e o local de sua veiculação, ou, ainda, proibindo inteiramente qualquer publicidade dirigida a crianças 15 . Uma revisão realizada sobre o cenário global das regulamentações verificou que 85\% dos 73 países pesquisados dispunham de alguma forma de regulamentação sobre publicidade televisiva dirigida às crianças e que quase a metade (44\%) tinha restrições específicas sobre o horário e o conteúdo veiculado 8 .

Com a aprovação da Estratégia Global da Organização Mundial da Saúde (OMS) sobre Dieta, Atividade Física e Saúde em 2004, governos e setores alimentícios e de publicidade de vários países vêm desenvolvendo políticas destinadas a regular o marketing de alimentos para crianças ${ }^{9}$. Pelo menos 26 governos já emitiram declarações explícitas sobre marketing de alimentos para crianças em documentos estratégicos; 20 desenvolveram ou estão desenvolvendo políticas na forma de medidas legais, diretrizes oficiais ou modelos aprovados de autorregulamentação 12 . Isso sinaliza que um conjunto amplo de atores apoia algum tipo de estratégia regulatória da publicidade de alimentos.

No Brasil, os instrumentos legais que normatizam a propaganda de alimentos datam desde a década de 1960, quando o Ministério da Saúde assumiu a competência de regular os textos e matérias desse tipo 16. Após a criação da Agência Nacional de Vigilância Sanitária (ANVISA), essa atribuição lhe foi transferida 17 , consolidando o texto constitucional que estabelece a obrigação do Estado de proteger a saúde da população e evitar a exposição a propagandas comerciais de produtos e serviços que possam influenciar de forma inadequada as práticas em saúde.

A partir da década de 1980, uma nova modalidade de regulação da publicidade passou a ser predominante no país, exercida pelo Conselho Nacional de Autorregulamentação Publicitária (CONAR. http://www.conar.org), uma organização não governamental, que se propõe a fiscalizar a ética da propaganda comercial veiculada no Brasil. O CONAR é integrado por agências de publicidade, anunciantes e veículos de comunicação, mas não conta com representantes de organizações da Sociedade Civil nem do Estado. 
Já o Código de Defesa do Consumidor apresentou, em 1990, elementos de proteção contra a publicidade enganosa e abusiva, incluindo a obrigação de fornecer informação adequada e clara sobre os diferentes produtos e serviços 18 . Posteriormente, entraram em vigor novas publicações que tratam da regulamentação da Promoção Comercial de Alimentos para Lactentes e Crianças de Primeira Infância e de produtos de puericultura correlatos 19,20. Contudo, não detalham os procedimentos para adequação da publicidade de alimentos, especialmente voltados ao público infantil acima de três anos, mais vulnerável aos apelos publicitários.

O Governo Federal desencadeou um processo, em 2005, protagonizado pela ANVISA, para elaboração de uma proposta de regulamentação da publicidade de alimentos não saudáveis e de bebidas de baixo valor nutricional. Essa proposta foi publicada em 2006 através de uma Consulta Pública (CP no 71/06) para que fossem apresentadas críticas e sugestões. A proposta versava especificamente "sobre a oferta, propaganda, publicidade, informação e a outras práticas correlatas cujo objeto seja a divulgação ou promoção de alimentos com quantidades elevadas de açúcar, de gordura saturada, de gordura trans, de sódio e de bebidas com baixo teor nutricional, quaisquer que sejam as formas e meios de sua veiculação..." 21.

O documento foi amplamente discutido e modificado, sendo aprovado somente quatro anos após a sua publicação, pela RDC no 24/2010 que dispõem "sobre a oferta, propaganda, publicidade, informação e outras práticas correlatas cujo objetivo seja a divulgação e a promoção comercial de alimentos considerados com quantidades elevadas de açúcar, de gordura saturada, de gordura trans, de sódio, e de bebidas com baixo teor nutricional..." 22.

Essa Resolução representou um grande avanço, mas foi suspensa por liminar da Justiça Federal de Brasília, a pedido da Associação Brasileira das Indústrias da Alimentação (ABIA), que questionou a competência da ANVISA para regular a questão. Um dos primeiros atores a solicitar a suspensão da Resolução foi o próprio CONAR que sempre se manifestou contrário a qualquer tipo de regulamentação estatal 23 . Dessa maneira, evidencia-se o conflito de interesses estabelecido entre a indústria de alimentos e setores de governo, diante de estratégias governamentais que têm como objetivo promover mecanismos de proteção ao direito à alimentação adequada $\mathrm{e}$ saudável, instituído na Constituição Brasileira e em Lei Orgânica 24.

Considerando a importância dessa temática, o presente estudo objetivou desenvolver uma análise comparativa entre o Regulamento proposto (CP no 71/2006) e a $R D C$ no $24 / 2010$, bem como identificar os atores, as contribuições e os argumentos apresentados ao longo do processo. A Resolução aprovada consiste no instrumento legal que expressa o pacto político possível após um longo período de consulta pública. Analisar inclusões e exclusões na proposta original contribui para compreender os pontos críticos em torno dos quais se estabelecem conflitos entre interesses de caráter público e privado de cunho comercial, particularmente os lucros empresariais advindos da publicidade e a comercialização de produtos industrializados.

\section{Métodos}

A análise se pautou em dados provenientes de documentos legais publicados pela ANVISA referentes à regulamentação da propaganda de alimentos e na identificação dos atores-chave que participaram dessa trajetória (que nasce com o projeto de regulamentação submetido à consulta pública e culmina na formulação da $R D C$ no 24/2010). A análise documental vem sendo amplamente empregada como método de construção de dados e documentos governamentais podem ser estratégicos para o campo da análise de políticas, quando considerados como práticas discursivas que sustentam estratégias de governabilidade 25 . Eles expressam questões que se tornaram politicamente relevantes e formalizam um pacto político possível num dado contexto. Logo, possibilitam identificar em que termos os atores apresentam sua argumentação e como se apropriam politicamente do texto formalizado. Indicam as posições políticas, concepções, valores, argumentos e interesses em disputa na agenda pública 26 . Analisar as mudanças que ocorreram em dois documentos oficiais do mesmo órgão contribui para identificar o peso político que os atores detêm para incluir, excluir questões e eventualmente embargar processos.

Com base em tais pressupostos, foram analisados os argumentos que pautaram os discursos de distintos atores envolvidos com o processo de formulação da legislação em questão, tanto no sentido favorável quanto contrário à proposta de regulamentação apresentada em 2006 pela ANVISA.

Para o cotejamento dos documentos, foram analisados a proposta de Regulamento Técnico publicado em 2006 que foi levada a Consulta Pública (CP no 71/2006) e o documento final aprovado e publicado pela $R D C$ no 24/2010. O conteúdo de cada um foi categorizado de acordo com as seguintes dimensões de análise: requisitos ge- 
rais, limites das propagandas e publicidade de alimentos; requisitos para a publicidade voltada às crianças; requisitos para a distribuição de produtos promocionais.

Para identificação dos diferentes atores e dos seus argumentos, utilizou-se o consolidado das contribuições referentes à Consulta Pública 27.

Para facilitar a redação, optou-se por substituir, em algumas situações, a expressão $C P$ no $71 / 2006$ por Regulamento proposto (RP) e $R D C n \underline{o}$ 24/2010 por Resolução aprovada (RA).

Foram analisados apenas documentos produzidos pela ANVISA, ainda que existam outros com natureza semelhante, construídos em espaços decisórios distintos, tais como o próprio Poder Legislativo. No entanto, esse material potencialmente expressa um processo político mais amplo, uma vez que atores de diferentes segmentos participaram da Consulta Pública e os documentos foram produzidos em duas conjunturas distintas com intervalo de quatro anos. O tempo decorrido pode indicar um contexto de conflito significativo, o que reforça a importância dessa análise.

Por pautar-se em análise documental, o estudo não explorou o conjunto de estratégias políticas adotadas pelos atores em diferentes espaços institucionais, ainda que tenham sido considerados elementos do contexto de produção do discurso oficial. De igual modo, não permitiu explorar as alianças políticas oriundas desse processo (que podem eventualmente ocasionar sobreposição de interesses privados em relação aos públicos), ainda que possibilidades do tipo sejam sinalizadas na discussão.

\section{Resultados}

Ao cotejar os dois documentos, identificou-se que de um modo geral o RP é mais detalhado e rigoroso sob o ponto de vista regulatório do que a RA. Não foram incluídos no texto final as proibições e exigências sobre o formato, o conteúdo e os temas das peças publicitárias, para a publicidade de alimentos, em especial as voltadas ao público infantil.

\section{Requisitos gerais}

O RP apresentava mais detalhes sobre a forma como as informações devem ser apresentadas nas peças publicitárias, seja na modalidade escrita ou oral tais como: a proporcionalidade das mensagens, tamanho da fonte utilizada, cores dos anúncios, tempo de duração e idioma nos diversos meios de comunicação. Já os requisitos gerais dispostos na RA não são tão detalhados, ainda assim destacam a necessidade de a peça publicitária ser adequada em termos de especificações sobre a proporcionalidade das mensagens em relação ao anúncio, a fácil compreensão, veracidade e objetividade da mensagem. Os dois documentos apresentam considerações relacionadas aos alertas sobre os perigos do consumo excessivo dos alimentos em questão.

\section{Limites das propagandas e publicidade de alimentos}

No item que trata dos requisitos gerais, destacam-se questões sobre os limites das propagandas e outras práticas correlatas. O Artigo 5o do RP e o Artigo 11o da RA, por intermédio de seus incisos, objetivam limitar determinadas práticas de promoção comercial de alimentos considerados não saudáveis e trazem informações sobre o que não pode constar em tais peças publicitárias e afins. Esses artigos se assemelham bastante e todos os incisos contemplados na RA também constam no RP. Contudo, o último é mais completo e detalhado e nele constam proibições (incisos IV, V, VI, VIII, IXa, Xa, XI, XII, XII, XIV) que não foram incluídas na RA.

\section{Requisitos para a publicidade voltada às crianças}

Os requisitos para a propaganda, publicidade ou promoção comercial destinada às crianças são expressos no Título II da Consulta Pública e no Capítulo III da RDC. Na RA, consta um único artigo referente à obrigatoriedade do alerta sobre o perigo do consumo excessivo de açúcar, gordura saturada, gordura trans, sódio e bebidas com baixo teor nutricional, com destaque para a contextualização do alerta na peça publicitária. Já o $\mathrm{RP}$ contém seis artigos que não foram incluídos na RA, que tratam da: utilização de figuras, desenhos e personagens cativos; limitação do horário de veiculação; proibição da propaganda/promoção em instituições de ensino ou de cuidados infantis; divulgação de brindes condicionados à aquisição dos alimentos em questão; realização de propaganda direcionada às crianças em brinquedos, filmes, jogos eletrônicos, páginas da internet e produção de material educativo, que façam alusão a esses alimentos.

\section{Requisitos para a distribuição de produtos promocionais}

Os requisitos para distribuição de amostras grátis, cupons de desconto, patrocínio e outras atividades promocionais estão previstos no Título III (Artigos 12o ao 16o ) do RP e nos Artigos 8o, 9o 
e 10o da RA. O Artigo 12o do RP prevê proibição para distribuição de amostras grátis, degustação e distribuição de cupons de desconto no caso dos alimentos em questão. Já no Artigo 8o da RA, a distribuição de amostras grátis desses alimentos é permitida, porém, é obrigatória a veiculação do alerta sobre o perigo do consumo excessivo dos nutrientes, a que se refere o Artigo 6o, que trata das exigências quanto à obrigatoriedade da propaganda ser direta e verdadeira, de forma a evidenciar o caráter promocional da mensagem; ser facilmente distinguível como tal, não importando a sua forma ou meio utilizado e que seja $(\mathrm{m})$ veiculado(s) alerta(s) sobre os perigos do consumo excessivo dos nutrientes em questão por meio de mensagens.

De acordo com a RP, não é permitido realizar propaganda, publicidade e promoção durante atividades educacionais ou esportivas, ou em qualquer outra atividade de divulgação que esteja relacionada a tais alimentos (Artigo 13o). Não é permitida a realização de programas de incentivo educacional ou esportivo que apresentem esses alimentos como prêmio, bonificação, brinde ou como qualquer outra forma de benefício (Artigo 14으. No Artigo 15o, é vedado o incentivo à aquisição de alimentos às instituições de ensino ou qualquer entidade destinada a fornecer cuidados às crianças. Também não é permitido mencionar nomes de alimentos na divulgação de campanhas sociais e informar a respeito de campanha social na propaganda, publicidade e promoção de alimentos (Artigos 15o e 16으).

Por outro lado, na RA, o Artigo 9o aponta que todo material publicitário referente ao patrocínio de fornecedores ou distribuidores dos alimentos em questão deve veicular o alerta exigido pelo Artigo 6o. A menção de nomes/marcas dos alimentos em questão em programas ou campanhas sociais e a promoção comercial desses alimentos são permitidas segundo o Artigo 10ọ, desde que sejam respeitadas as disposições da RA.

\section{Os principais atores e suas contribuições}

O RP ficou disponível por 140 dias e recebeu 254 contribuições procedentes de 248 contribuintes, e seis deles deram duas contribuições. Na análise do consolidado, os 248 contribuintes foram classificados em quatro grupos, sendo: 71 pessoas físicas; 62 representantes da sociedade organizada, instituições governamentais e de ensino; 35 instituições de combate ao câncer; 80 representantes do setor regulado.

Pela característica das contribuições, identificou-se que 108 contribuintes foram favoráveis, 121 emitiram contribuições contrárias ao regulamento e nove apresentaram dúvidas, solicitaram prorrogação de prazo e realizaram um abaixoassinado em favor da regulamentação. Constatou-se que dez manifestantes não enviaram contribuição, seus nomes apenas constavam no documento.

A maioria (54\%) das manifestações a favor da regulamentação foi proveniente de pessoas físicas, seguida da sociedade organizada (45\%) representada pelas áreas de nutrição, odontologia e cardiologia e de instituições de defesa do consumidor. Apenas um contribuinte do setor regulado foi a favor da regulamentação. Dos grupos contrários, $61 \%$ integravam o setor regulado, $7 \%$ de pessoas físicas e $2 \%$ pertenciam à sociedade organizada. Destaca-se que 35 instituições de apoio e tratamento ao câncer, representadas pelas fundações, associações e entidades civis sem fins lucrativos de combate ao câncer se manifestaram contrárias ao regulamento.

A natureza das contribuições foi distinta, dependendo do posicionamento em relação à regulamentação da publicidade de alimentos. As principais manifestações contrárias se referiam a retirada de artigos e parágrafos (49\%), exclusão de todo regulamento (13\%), e destaque para a orientação nutricional como estratégia prioritária ao consumo de alimentos saudáveis (10\%), dentre outras sugestões menos expressivas. Quanto às manifestações favoráveis, mais da metade (51\%) se referia a ajustes na redação, $17 \%$ foram de apoio e congratulação pelo instrumento regulador, além de contribuições referentes à necessidade de ampliar os alertas ao consumo excessivo de determinados alimentos (6\%), a inclusão da definição de termos técnicos (6\%), dentre outras.

\section{Discussão}

Evidenciou-se uma lacuna na RA, visto que após longo período de discussões com a sociedade, não foram incluídos os elementos presentes no texto do RP que tratavam especificamente da publicidade direcionada à criança. Ao não incluir as disposições relevantes do capítulo referente à publicidade dirigida à criança, a ANVISA coloca o Brasil em descompasso com as discussões ocorridas nacional e internacionalmente sobre o tema.

A formulação de políticas sociais é um processo dinâmico que configura e expressa projetos políticos em disputa, conflitos e convergências de concepções e interesses. Os diferentes governos respondem a esse processo de uma forma que não é linear, nem "coerente", podendo parecer até mesmo contraditória em relação aos objetivos formalizados nas políticas sociais. 
O processo decisório é também condicionado pelas concepções que são socialmente construídas em torno do que cabe ao Estado, de como ele deve intervir nas práticas sociais e dos instrumentos e mecanismos governamentais que são considerados mais adequados a cada campo de políticas em cada contexto. Essas concepções e interesses não são estáticos. Nesse sentido, a reflexão sobre como se constrói a política social, qual o papel do Estado, quais os parâmetros éticos que devem pautar as relações entre os governos e setores comerciais é fundamental.

No caso da publicidade de alimentos, o jogo de interesses se expressa tanto no poder legislativo (lobby das indústrias de alimentos) quanto no poder executivo (ministérios) e institucionalmente tem as agências reguladoras como interlocutores ou agentes de fiscalização. Neste contexto, o Ministério da Saúde por meio da ANVISA e o Ministério de Agricultura, Pecuária e Abastecimento respondem como interlocutores da sociedade com o mercado 28 . As agências reguladoras criam instrumentos que promovem uma regulação pública de práticas sociais e são considerados medidas de proteção, pois estabelecem limites em torno dos riscos em saúde provenientes da ação de terceiros 15 .

O mapeamento dos atores participantes da consulta pública ratifica um fato já destacado por Gomes et al. 23 de que nenhuma empresa transnacional de bebidas e alimentos processados se manifestou no curso desse processo. No ramo das indústrias de alimentos, manifestaram-se a ABIA e a Associação Brasileira das Indústrias de Refrigerantes e de Bebidas Não Alcoólicas, além de empresas e entidades ligadas ao setor de comunicação e publicidade 23 .

O estudo de Henriques et al. 29 , que analisou as propagandas de produtos alimentícios destinadas ao público infantil veiculadas na mídia televisiva, verificou que todas as propagandas foram consideradas abusivas porque infringiram pelo menos três artigos do RP, indicando que as práticas da indústria alimentícia ferem os princípios defendidos pela ANVISA, o que reitera seu interesse contrário a qualquer tipo de ação regulatória.

A presente análise indicou que parte dos argumentos utilizados pelos atores contrários à regulamentação influenciou o conteúdo da RA. Os vetos e proibições especialmente voltados ao público infantil foram retirados ou sofreram novas redações, ficando menos restritivos.

Ao longo da Consulta Pública, representantes da indústria de alimentos apresentaram desde comentários específicos sobre artigos e incisos até a insatisfação total com o documento inicialmente proposto pela ANVISA. O documento final expressa em certa medida o resultado da pressão de tais grupos (interessados em manter o atual perfil da publicidade no Brasil). A análise do documento que consolidou as contribuições à Consulta Pública indicou que determinados atores apresentaram convergência de interesses e concepções com o RP e defenderam seus princípios, sobretudo as organizações da sociedade civil.

Entretanto, os atores contrários foram mais numerosos, destacando-se as instituições de apoio e tratamento ao câncer (com exceção do Instituto Nacional de Câncer), representadas pelas fundações, associações e entidades civis sem fins lucrativos, que, interessadas na manutenção do financiamento proveniente de empresas de alimentos, solicitaram a exclusão dos Artigos $15 \mathrm{e}$ 16 da RP, que tratam: da proibição de campanhas de cunho social, condicionadas a aquisição de alimentos; da vinculação de nomes de alimentos na divulgação de campanhas e da proibição de informar a respeito delas na propaganda, publicidade e promoção de alimentos. As solicitações de exclusão dos dois artigos foram atendidas na RA, indicando a possível articulação política do setor privado com setores do governo.

$\mathrm{O}$ setor regulado, mediante diversos argumentos, objetivou garantir seus interesses e demonstrar seu posicionamento contrário ao RP e os atores favoráveis reforçaram a necessidade de instrumentos de proteção e promoção da alimentação saudável, indicando os distintos interesses em jogo que tensionam lucro e saúde.

Uma das linhas de argumentação contrária a $\mathrm{RP}$ questiona a própria legitimidade da ANVISA enquanto órgão competente para exercer a regulamentação da publicidade. Segundo Santos 30, os termos regulação, regular, normatizar, dentre outros termos legais, indicam que o Poder Público pode e em alguns casos deve atuar normativamente na salvaguarda dos interesses coletivos, por vezes impondo condicionamentos administrativos à atividade individual ou de um setor.

Todavia, as iniciativas legislativas encontram entraves por parte de alguns setores de comunicação e publicidade, que as concebem como uma ingerência do Estado à liberdade econômica dos agentes privados e alegam censura à "liberdade de expressão comercial" 31. Esse argumento é sustentado tanto por segmentos das indústrias/empresas de alimentos, quanto por alguns segmentos do setor publicitário que têm como prática precípua a utilização de estratégias de marketing. Outro argumento dos agentes comerciais e do setor publicitário é a existência do CONAR e a possibilidade de esse órgão exercer a autorregulamentação do setor. Em oposição, pode-se justificar a regulação governamental tendo em vista que dificilmente um órgão estabelecido 
pelo próprio setor regulado pode exercer essa função, dado o conflito de interesses públicos e privados/de caráter comercial.

Gomes et al. 23 também indicaram que os principais atores contrários à regulamentação apresentaram os seguintes argumentos: todos os alimentos quando consumidos de forma "equilibrada” são saudáveis; as decisões em torno do consumo são de responsabilidade individual e a ANVISA não tem o poder legal para dispor sobre publicidade de alimentos.

Cabe destacar que o próprio Conselho Nacional de Saúde (CNS), um órgão de controle social do Sistema Único de Saúde, publicou a Resolução CNS no 408/2008 com intuito de coibir práticas que contribuam com perfis de consumo incompatíveis com a saúde e que violem o direito à alimentação adequada. Dentre elas, a regulamentação da publicidade, propaganda e informação sobre alimentos que são direcionadas ao público em geral e em especial ao público infantil 32.

A regulação da publicidade de produtos considerados de risco para a saúde necessita de ser analisada também à luz de parâmetros éticos que considerem o direito à informação e à saúde e que possibilitem integrar ações voltadas para minimizar os diferentes riscos advindos do consumo induzido de forma indiscriminada ${ }^{6}$. O Brasil dispõe de instrumentos legais que intentam proteger o aleitamento materno e reduzir o uso do tabaco e do álcool; nessa trajetória, a indústria também vem se utilizando de distintas estratégias para contornar a regulação. Nesses casos, os avanços são diferentes por razões que precisam ser melhor estudadas, dado que se trata de questões de natureza distinta e igualmente diferenciadas em termos de tempo e nível de profundidade do debate público.

No caso da regulamentação da publicidade de alimentos, deve-se considerar a vulnerabilidade do público infantil às estratégias agressivas de marketing. Os parâmetros que pautaram a proposta da ANVISA, e que não foram incluídos na $\mathrm{RA}$, indicavam uma perspectiva de regulamentação como um mecanismo de proteção a tal público. Os dispositivos objetivavam inclusive coibir as estratégias publicitárias que exploram aspectos subjetivos das práticas e das relações sociais, a exemplo da forma como abordam a relação das crianças com os próprios pais. Alguns comerciais induzem as crianças a se utilizarem de estratégias como chantagem e manipulação para que seus pais comprem um determinado produto. Os mecanismos regulatórios pretendiam proteger crianças da exposição, ao longo da sua vida, às práticas publicitárias dessa natureza que, para alcançar o objetivo da venda, utilizam-se de estratégias indiscriminadas de estímulos ao consumo.
Dessa forma, na fase adulta, sua capacidade crítica e sua autonomia decisória não seriam tão marcadas por um perfil de práticas alimentares que reforça o uso de produtos industrializados, e que, por diferentes motivos, consegue ocupar majoritariamente os meios de comunicação de massa 29.

Embora estudos indiquem a relação entre exposição à publicidade e consumo, há poucas evidências publicadas sobre o efeito das proibições publicitárias na alimentação infantil ${ }^{8}$. A análise dos princípios que pautam os mecanismos regulatórios propostos pela ANVISA indica que o objetivo é evitar que a propaganda de alimentos venha a induzir um determinado perfil de consumo de alimentos não saudáveis e, mais ainda, um consumo indiscriminado desses alimentos. Avalia-se que informações adequadas e bem compreendidas podem contribuir para que o ato de consumir seja acompanhado de uma atitude de reflexão sobre os múltiplos condicionantes das práticas alimentares.

\section{Considerações finais}

A análise aqui apresentada sinaliza elementos que podem ser úteis à compreensão de políticas de alimentação e nutrição, dentre eles, como se constroem socialmente os limites e as possibilidades de atuação do Estado, bem como as relações entre governos e setor comercial.

As interfaces entre interesses públicos e privados atravessam redes de políticas que articulam atores não governamentais e governamentais, considerando inclusive que os governos não são homogêneos. A dinâmica política que então se estabelece condiciona em grande medida o tempo e a possibilidade dos diferentes tipos de intervenção estatal que são implementadas. No caso da regulamentação da publicidade de alimentos, o longo tempo decorrido e a baixa capacidade de reação frente aos embates sofridos indicam as fortes limitações da ação governamental nessa questão e o peso significativo das disputas políticas em pauta.

As associações que representam os interesses das indústrias de alimentos e do setor de empresas de comunicação e publicidade protagonizam um processo político destinado à redução do campo de intervenção estatal na regulamentação da publicidade de alimentos.

A análise dos argumentos dos atores no curso da consulta pública revela que os interesses que estão em jogo no âmbito da regulamentação da publicidade são de múltiplas ordens. Um conjunto significativo de questões que está em pauta neste campo é de natureza econômica, uma 
vez que os mecanismos regulatórios implicam algum risco de redução dos lucros por parte das indústrias/empresas de alimentos.

Outra ordem de fatores se refere ao sistema de valores e práticas socialmente construídos. A defesa de princípios como "liberdade de expressão", "liberdade individual", "liberdade de escolha" em torno das decisões que conformam a esfera do consumo, assumiu lugar estratégico na argumentação política dos atores contrários à regulamentação. A possibilidade de influência mais disseminada de tais argumentos é, por sua vez, condicionada pelos múltiplos sentidos que assumem num determinado contexto e conjuntura histórica. Por outro lado, não há como ignorar que, ao propor que sejam retiradas das propagandas frases que induzam a criança a manipular seus pais, os atores que apoiam a regulamentação sinalizam outros aspectos desse embate. Demonstram que o modo como as práticas publicitárias vêm se estabelecendo fomenta uma determinada ética que afeta as relações sociais basilares, como aquelas que se estabelecem na família. As empresas de comunicação e publicidade almejam atingir estrategicamente o público infantil e dispõem de recursos desiguais, quando comparadas a qualquer outro setor, considerando os custos de uma propaganda nos meios de comunicação de massa. Portanto, não há nesse ambiente coletivo e público, que se estabelece por intermédio dos meios de comunicação, um convívio "equilibrado" de diferentes perspectivas éticas em torno do consumo, mas sim uma massificação de determinados valores.
As tensões políticas desse processo também devem ser levadas em conta, pois um mecanismo regulatório é um dispositivo de exercício de poder e implica controle sobre determinadas práticas sociais. Logo, trata-se de um processo de cerceamento de poder de influência dos segmentos regulados. Ainda que possam ampliar sua esfera de poder mediante outros mecanismos, como, por exemplo, pela via das redes de interesses que se constroem "por dentro" do governo e que atravessam as práticas institucionais, $o$ poder de influência dos meios de comunicação de massas não é de forma alguma desprezível. Além disso, qualquer instrumento que reitere a capacidade regulatória do Estado pode significar, mesmo que simbolicamente, uma possibilidade de expansão do campo de poder e de controle governamental.

A utilização da ilegalidade como argumento, no caso o questionamento da atribuição regulatória da ANVISA, reflete a complexidade desse cenário. Para impedir o processo que está em curso, tais atores se utilizam de uma estratégia que desvirtua a discussão em torno do mérito da proposta e coloca no centro do embate um argumento de outra ordem.

Por conseguinte, fortalecer a discussão sobre o que é a esfera pública, como ela se constrói, o que são interesses públicos e quais os mecanismos e processos que podem contribuir para garanti-los, parece relevante no contexto brasileiro. 


\section{Resumen}

El objetivo del estudio fue desarrollar un análisis comparativo entre el documento propuesto para regular la publicidad de alimentos poco saludables y bebidas de bajo valor nutricional, sobre el que se realizó una consulta pública en 2006, y la resolución adoptada al respecto en 2010. El análisis se basó en datos de documentos legales relacionados con la regulación de la publicidad de alimentos, identificación de los actores y argumentos fundamentales que guiaron sus discursos. Se encontró que la resolución adoptada se presenta menos detallada y exacta desde el punto de vista reglamentario. Se eliminaron las prohibiciones y requisitos sobre el formato, el contenido y los temas sobre publicidad de alimentos, especialmente los dirigidos a los niños. Es necesario fortalecer la discusión de lo que es la esfera pública, ya que se basa en cuáles son los intereses públicos y qué mecanismos y procesos pueden contribuir a garantizarlos.

Control de la Publicidad de Productos; Seguridad

Alimentaria; Anuncios

\section{Colaboradores}

P. Henriques, P. C. Dias e L. Burlandy participaram da concepção do estudo, análise e interpretação dos dados e redação do artigo

\section{Referências}

1. Instituto Brasileiro de Geografia e Estatística. Pesquisa de Orçamentos Familiares 2008-2009: antropometria e estado nutricional de crianças, adolescentes e adultos no Brasil. Rio de Janeiro: Instituto Brasileiro de Geografia e Estatística; 2010.

2. World Health Organization. Global status report on non communicable diseases 2010. Geneva: World Health Organization; 2011.

3. Departamento de Análise de Situação de Saúde, Secretaria de Vigilância em Saúde, Ministério da Saúde. Plano de ações estratégicas para o enfrentamento das doenças crônicas não transmissíveis (DCNT) no Brasil 2011-2022. Brasília: Ministério da Saúde; 2011.

4. Drewnowski A, Darmon N. The economics of obesity: dietary energy density and energy cost. Am J Clin Nutr 2005; 82:265-73.

5. Vasconcellos AB, Goulart D, Gentil PC, Oliveira TP. A saúde pública e a regulamentação da publicidade de alimentos. http://189.28.128.100/nutri cao/docs/geral/regulamentaPublicidadeAlimen tos.pdf (acessado em 06/Out/2009)
6. Marins BR, Araújo IS, Jacob SC. A propaganda de alimentos: orientação, ou apenas estímulo ao consumo? Ciênc Saúde Coletiva 2011; 16:3873-82.

7. World Health Organization. Diet, nutrition and the prevention of chronic diseases. Geneva: World Health Organization; 2003. (WHO Technical Report Series, 916).

8. Hawkes C. Marketing de alimentos para crianças: o cenário global das regulamentações. Brasília: Organização Pan-Americana da Saúde/Agência Nacional de Vigilância Sanitária; 2006.

9. Organização Pan-Americana da Saúde. Recomendações da consulta de especialistas da Organização Pan-Americana da Saúde sobre a promoção e a publicidade de alimentos e bebidas não alcoólicas para crianças nas Américas. Washington DC: Organização Pan-Americana da Saúde; 2012.

10. Costa SMM, Horta PM, Santos LC. Food advertising and television exposure: influence on eating behavior and nutritional status of children and adolescents. Arch Latinoam Nutr 2012; 62:53-9. 
11. Bridget K, Halford JCG, Boyland EJ, Chapman K, Bautista-Castaño I, Berg C, et al. Television food advertising to children: a global perspective. Am J Public Health 2010; 100:1730-6.

12. Hawkes C, Lobstein T. Regulamentação da promoção comercial de alimentos para crianças: levantamento das ações em todo o mundo. Int J Pediatr Obes 2010; 6:83-94.

13. Menéndez García RA, Franco Diez FJ. Publicidad y alimentación: influencia de los anuncios gráficos en las pautas alimentarias de infancia y adolescencia. Nutr Hosp 2009; 24:318-25.

14. Wiecha JL, Peterson KE, Ludwig DS, Kim J, Sobol A, Gortmaker SL. When children eat what they watch: impact of television viewing on dietary intake in youth. Arch Pediatr Adolesc Med 2006; 160:436-42.

15. Monteiro CA, Castro IRR. Por que é necessário regulamentar a publicidade de alimentos. Ciênc Cult (São Paulo) 2009; 61:56-9.

16. Ministério da Saúde. Decreto-Lei no 986, de 21 de outubro de 1969. Institui normas básicas sobre alimentos. Diário Oficial da União 1969; 21 out.

17. Presidência da República. Lei no 9.782 , de 26 de janeiro de 1999. Define o Sistema Nacional de Vigilância Sanitária, cria a Agência Nacional de Vigilância Sanitária, e dá outras providências. Diário Oficial da União 1999; 27 jan.

18. Presidência da República. Lei no 8.078, de 11 de setembro de 1990. Código de Defesa do Consumidor. Dispõe sobre a proteção do consumidor e dá outras providências. Diário Oficial da União 1990; 12 set.

19. Agência Nacional de Vigilância Sanitária. Resolução RDC no 222, de 5 de agosto de 2002. Aprova o regulamento técnico para promoção comercial de alimentos para lactentes e crianças de primeira infância. Diário Oficial da União 2002; 6 ago.

20. Presidência da República. Lei no 11.265 , de 3 de janeiro de 2006. Regulamenta a comercialização de alimentos para lactentes e crianças de primeira infância e também a de produtos de puericultura correlatos. Diário Oficial da União 2006; 4 jan.

21. Agência Nacional de Vigilância Sanitária. Consulta Pública no 71, de 10 de novembro de 2006. Proposta de regulamento técnico sobre oferta, propaganda, publicidade, informação e outras práticas correlatas cujo objeto seja a divulgação ou promoção de alimentos com quantidades elevadas de açúcar, de gordura saturada, de gordura trans, de sódio e de bebidas com baixo teor nutricional, quaisquer que sejam as formas e meios de sua veiculação. Diário Oficial da União 2006; 13 nov.

22. Agência Nacional de Vigilância Sanitária. Resolução RDC no 24, de 15 de junho de 2010. Dispõe sobre a oferta, propaganda, publicidade, informação e outras práticas correlatas cujo objetivo seja a divulgação e a promoção comercial de alimentos considerados com quantidades elevadas de açúcar, gordura saturada, gordura trans, sódio e de bebidas com baixo teor nutricional. Diário Oficial da União 2010; 14 jul.
23. Gomes FS, Castro IRR, Monteiro CA. Publicidade de alimentos no Brasil: avanços e desafios. Ciênc Cult (São Paulo) 2010; 62:48-51.

24. Presidência da República. Lei no 11.346 de 15 de setembro de 2006. Cria o Sistema Nacional de Segurança Alimentar e Nutricional - SISAN com vista a assegurar o direito humano à alimentação adequada e dá outras providências. Diário Oficial da União 2006; 18 set.

25. Spink MJ, Menegon VM. Práticas discursivas como estratégia de governamentalidade: a linguagem dos riscos em documentos de domínio público. In: Iniguez L, organizador. Análise do discurso em ciências sociais. Petrópolis: Editora Vozes; 2005. p. 258-303.

26. Freeman R, Maybin J. Documents, practices and policy. Evid Pol 2011; 7:155-70.

27. Agência Nacional de Vigilância Sanitária. Consolidado da Consulta Pública no 71/2006/GPROP/ ANVISA/MS. http://www.anvisa.gov.br/propa ganda/Contribuicoes_CP71_VersaFinal_RF.pdf (acessado em 16/Mar/2009).

28. Pinheiro ARO, Carvalho DBB. Estado e mercado: adversários ou aliados no processo de implementação da Política Nacional de Alimentação e Nutrição? Elementos para um debate sobre medidas de regulamentação. Saúde Soc 2008; 17:170-83.

29. Henriques P, Sally EO, Burlandy L, Beiler RM. Regulamentação da propaganda de alimentos infantis como estratégia para a promoção da saúde. Ciênc Saúde Coletiva 2012; 17:481-90.

30. Santos L. O poder regulamentador do Estado sobre as ações e os serviços de saúde. In: Fleury S, organizador. Saúde e democracia: a luta do CEBES. São Paulo: Lemos Editorial; 1997. p. 241-79.

31. Henriques IVM. Controle social e regulação da publicidade infantil. O caso da comunicação mercadológica de alimentos voltada às crianças brasileiras. RECIIS Revista Eletrônica de Informação \& Inovação em Saúde 2010; 4:72-84.

32. Conselho Nacional de Saúde, Ministério da Saúde. Resolução CNS no 408, de 11 de dezembro de 2008. Aprova diretrizes para a promoção da alimentação saudável com impacto na reversão da epidemia de obesidade e prevenção das doenças crônicas não transmissíveis. Diário Oficial da União 2009; 9 mar.

Recebido em 08/Jan/2013

Versão final reapresentada em 14/Nov/2013

Aprovado em 03/Dez/2013 